\title{
A UTILIZAÇÃO DA MÚSICA E DA METODOLOGIA INVESTIGATIVA PARA O ENSINO DOS IMPACTOS AMBIENTAIS NA VEGETAÇÃO
}

André Maciel da Silva ${ }^{1}$

\author{
Antonio Fernandes Nascimento Junior ${ }^{2}$
}

\begin{abstract}
RESUMO
Com intuito de elaborar metodologias não expositivas, o presente trabalho tem como objetivo o planejamento, a ministração e a avaliação de uma prática pedagógica alternativa. Neste trabalho, a música e o método investigativo foram utilizados como estratégias para abordar a influência dos impactos ambientais na vegetação. A prática foi proposta na disciplina Metodologia do Ensino em Botânica (GBI-121) oferecida aos alunos de Ciências Biológicas (Licenciatura) da Universidade Federal de Lavras - MG (UFLA). A proposta da aula foi trabalhar alguns impactos ambientais e a influência que eles têm sobre a vegetação. Para dar início às discussões, foi utilizada a música Sobradinho, de Sá e Guarabyra. A partir da música, foram discutidos os impactos socioambientais causados pelas usinas hidrelétricas, presentes na letra da canção. Foram discutidos também outros impactos ambientais como as plantações de eucalipto, as queimadas, o descarte de lixo e a construção civil, que estão presentes na sociedade atual e principalmente na região de Lavras - MG. Ao final da prática, os alunos que participaram da atividade construíram uma paródia da música utilizada, destacando os impactos ambientais tratados durante a aula. Para terminar, os participantes avaliaram a prática. Através da
\end{abstract}

\footnotetext{
${ }^{1}$ Graduando em Ciências Biológicas (Licenciatura), Universidade Federal de Lavras, MG. andremaciel_29@hotmail.com 2 Professor Adjunto do Departamento de Biologia, Universidade Federal de Lavras, MG. toni_nascimento@yahoo.com.br análise das avaliações e dos resultados obtidos, foi possível perceber a importância e necessidade da utilização de metodologias não expositivas no que diz respeito a aproximar o aluno do conhecimento e instigá-lo a participar das atividades propostas pelo professor.
} 
PALAVRAS-CHAVE: Educação ambiental. Ensino de Ciências e Biologia. Música no ensino.

\title{
USE OF MUSIC AND INVESTIGATIVE METHODOLOGY FOR TEACHING ABOUT ENVIRONMENTAL IMPACTS ON VEGETATION
}

\begin{abstract}
On the intention of preparing non-expository methods, this paper aims at planning, applying and evaluating an alternative pedagogical practice. In this paper, the music and the investigative method were used as strategies to address the influence of the environmental impacts on vegetation. The practice was proposed on the discipline of Methodology of Teaching of Botany (GBI-121) offered to students of Biological Sciences (BSC) at the Federal University of Lavras - (UFLA). The proposal was to work about some environmental impacts and the influence they have on vegetation. To start the discussion, the music Sobradinho, of Sá and Guarabyra, was used. From the music, there was a discussion about the social and environmental impacts of hydroelectric plants, present in the lyrics of the song. It was also discussed other environmental impacts, such as eucalyptus plantations, fire, waste disposal and constructions, which are present in our society, especially in Lavras - MG. At the end of practice, the students who participated in the activity built a parody of the music used, highlighting the environmental impacts addressed in the classroom. Finally, the participants evaluated the practice. Through the analysis of the evaluations, it was possible to realize the importance and the necessity of using non-expository methods with the objective to approximate student and knowledge and spur him on to participate in the activities proposed by the teacher.
\end{abstract}

KEY-WORDS: Environmental education. Teaching of Science and Biology. Music in education.

\section{USO DE LA MÚSICA Y LA METODOLOGÍA DE INVESTIGACIÓN PARA LA ENSEÑANZA DE IMPACTOS AMBIENTALES EN LA VEGETACIÓN}

\section{RESUMEN}

Con el fin de preparar métodos no expositivos, este trabajo tiene como objetivo la planificación, administración y evaluación de una práctica pedagógica alternativa. En este trabajo, la música y el método de investigación se utilizaron como estrategias para hacer frente a la influencia de los impactos ambientales sobre la vegetación. La práctica se propuso en la disciplina Metodología de la Enseñanza en Botánica (GBI-121) ofrecida a los estudiantes de Ciencias Biológicas de la Universidad Federal de Lavras - (UFLA). La propuesta fue trabajar algunos de los impactos ambientales y la influencia que tienen sobre la vegetación. Para iniciar el debate, se utilizó la música Sobradinho, de Sá y Guarabyra. A partir de la música, fueron discutidos los impactos sociales y ambientales de las centrales hidroeléctricas, presentes en la letra de la canción. Fueron también discutidos otros impactos ambientales, como las plantaciones de eucaliptos, incendios, eliminación de basura y la construcción, que están presentes en nuestra sociedad y especialmente en Lavras - MG. Al final de la práctica, los estudiantes que participaron en la actividad construyeron una parodia de la música utilizada, destacando los impactos ambientales tratados en clase. Por último, los participantes evaluaron la práctica. A través del análisis de las valoraciones de los 
resultados obtenidos, se pudo comprender la importancia y necesidad de la utilización de métodos no expositivos con respecto a la aproximación de los conocimientos del alumno y estimularlo a participar en las actividades propuestas por el profesor.

PALABRAS-CLAVE Educación ambiental. Enseñanza de la ciencia y la biología. Música en la educación.

\section{INTRODUÇÃO E OBJETIVOS}

Atualmente, um dos maiores problemas enfrentados pelos professores, de maneira geral, é a utilização de práticas expositivistas, que tornam a aula cansativa, descontextualizada e com pouca interação entre aluno e professor. Como consequência dessa prática, o aluno acaba não construindo e aprendendo de fato 0 conhecimento.

Dessa maneira, torna-se necessário que os professores aceitem o desafio de abandonar esse modelo de prática, tendo como consequência uma aula que envolva mais o aluno, trazendo os conteúdos à sua realidade. Nessa perspectiva, os autores Oliveira e Coutinho (2009), destacam que os professores devem desenvolver recursos didáticos capazes de instigar o interesse dos alunos, através de ferramentas que melhorem o processo de ensino/aprendizagem.

Dentre os recursos que tem tal capacidade está a música. Muitos autores defendem a utilização da música no ensino. Parize (2003) destaca que a música é uma estratégia pedagógica que auxilia o professor no ensino, pois estimula o cérebro e permite o desenvolvimento de habilidades gerais do aluno. Tal pensamento vai de encontro com o trabalho de Ferreira (2008) no qual discorre que a prática de associar qualquer disciplina à música demonstra grande potencial, auxiliando no aprendizado, despertando e desenvolvendo nos alunos sensibilidades mais aguçadas na observação de questões. Tendo como base as questões levantadas por esses autores, é possível estimular o pensamento crítico e reflexivo dos alunos, através da análise da música, permitindo que eles busquem compreender ideias que são trazidas pelos versos da música, relacionando-as ao conteúdo da disciplina que está sendo tratada. Ainda nesse sentido, Morin (2000) traz em seu trabalho que em toda grande obra, seja de música, literatura, cinema, poesia ou pintura, há um pensamento profundo sobre a condição 
humana. Dessa maneira, ao utilizar alguma dessas como estratégia pedagógica, tornase mais fácil aproximar os alunos do conhecimento, uma vez que essas estratégias refletem sobre questões presentes no contexto social dos seres humanos e que dialogam diretamente com a disciplina.

Buscando ainda mais a aproximação entre professor e aluno, além da participação do mesmo durante a prática, o professor deve buscar por metodologias que tem esse objetivo. Uma delas é a investigação. Segundo Bell et al. (1986), a metodologia investigativa se resume, essencialmente, nas ideias que os alunos possuem e não no conhecimento que não possuem, trazendo para as aulas sua perspectiva sobre o assunto. Dessa maneira, através da utilização do conhecimento prévio do aluno, é possível aproximá-lo da prática, o estimulando a participar ativamente do processo de construção do conhecimento.

Com intuito de exercitar a utilização de estratégias pedagógicas não expositivas e dialogando com os Parâmetros Curriculares Nacionais (PCN), o objetivo desse trabalho foi elaborar uma aula, utilizando uma metodologia não expositiva, para trabalhar alguns conceitos ecológicos descritos no PCN. A prática foi proposta aos alunos da disciplina Metodologia do Ensino em Botânica (GBI-121) do curso de Ciências Biológicas (Licenciatura) da Universidade Federal de Lavras - MG (UFLA).

No presente trabalho, a estratégia escolhida foi a música, que aliada ao método investigativo, deveria ser aplicada ao tema influência dos impactos ambientais na vegetação.

\section{DESENVOLVIMENTO}

O desenvolvimento da metodologia se deu ao longo de um semestre letivo e foi dividida em quatro momentos: escolha do tema e estratégia pedagógica, apresentação do plano de aula, ministração da aula e avaliação da aula.

\section{Primeiro momento: escolha do tema e estratégia pedagógica}


O tema escolhido foi influência dos impactos ambientais na vegetação e a estratégia pedagógica escolhida foi a música. O conteúdo a ser trabalhado na prática foi baseado no Conteúdo Básico Comum (CBC), uma proposta curricular norteada pelo PCN que foi elaborada para as escolas públicas do estado de Minas Gerais. De acordo com o documento, o tema proposto está relacionado ao tópico "Impactos ambientais e extinção de espécies", onde é destacado que o aluno deve interpretar informações de diferentes fontes sobre transformações nos ambientes provocadas pela ação humana $e$ que tem relação com o risco de extinção de espécies. Além disso, na maioria das vezes os impactos ambientais estão ligados diretamente aos seres humanos e à necessidade de produção de energia. Nessa perspectiva, existe outra proposta do CBC que destaca a necessidade de que o professor destaque, discuta e compare os impactos ambientais causados por usinas geradoras de energia elétrica, associando esses impactos ao uso intensivo da mesma.

\section{Segundo momento: apresentação do plano de aula}

Após a escolha do tema e estratégia, os alunos da disciplina deveriam planejar uma aula e apresentar o planejamento no III Simpósio de Práticas de Ensino de Ciências e Biologia, realizado no Museu de História Natural (MHN) da UFLA. Neste evento, estavam presentes os alunos da disciplina e os bolsistas do Programa Institucional de Bolsas de Iniciação à Docência (PIBID) de Biologia. Cada aluno tinha vinte minutos para apresentar seu planejamento. Nesse momento, os alunos deveriam apresentar um projeto de aula, indicando a metodologia utilizada, o tema, os conceitos que seriam trabalhados e as etapas da aula. Após a apresentação, os ouvintes deveriam fazer críticas, sugestões e perguntas aos prelecionistas, em um período de dez minutos. O objetivo dessa etapa foi avaliar o planejamento, de forma a acertar alguns detalhes apontados pelos ouvintes e preparar os alunos da disciplina para a terceira etapa. 


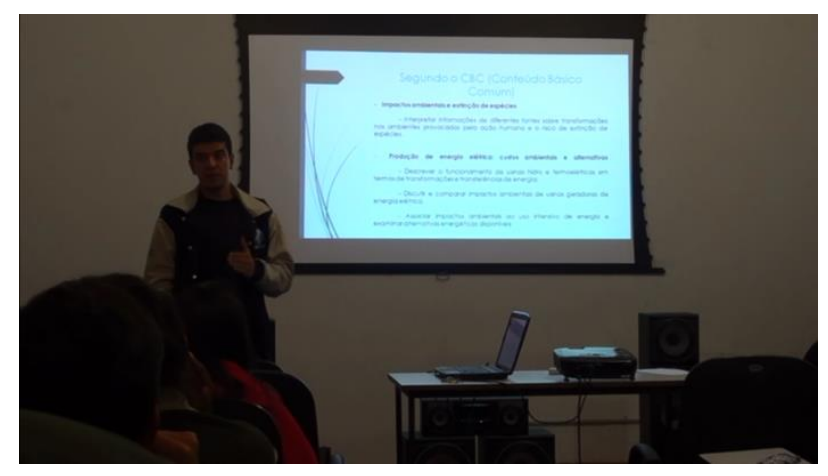

Fig. 1: apresentação do plano de aula no Simpósio.

Terceiro momento: ministração da aula

A aula teve duração de 50 minutos e foi desenvolvida com o docente responsável pela disciplina e os outros alunos matriculados na mesma. Nesse momento, o aluno que planejou a aula seria o professor e o restante os alunos.

Inicialmente houve uma conversa com os alunos explicando como a aula aconteceria. Durante essa conversa, o professor entregou aos alunos cópias de um trecho da letra da música Sobradinho, de Sá e Guarabyra. Explicou a eles que a partir da música, as discussões da aula surgiriam. Em seguida, o professor apresentou a música aos alunos. 
Titulo: Sobradinho

Composição: Sá \& Guarabyra

O homem chega, já desfaz a natureza

Tira gente, põe represa, diz que tudo vai mudar

o São Francisco lá pra cima da Bahia

Diz que dia menos dia vai subir bem devagar

E passo a passo vai cumprindo a profecia

do beato que dizia que o Sertão ia alagar

O sertão vai virar mar, dá no coração

O medo que algum dia o mar também vire sertão

Adeus Remanso, Casa Nova, Sento-Sé

Adeus Pilão Arcado vem o rio te engolir

Debaixo d'água lá se vai a vida inteira

Por cima da cachoeira o gaiola vai, vai subir

Vai ter barragem no salto do Sobradinho

E o povo vai-se embora com medo de se afogar.

Remanso, Casa Nova, Sento-Sé

Pilão Arcado, Sobradinho

Adeus, Adeus ..

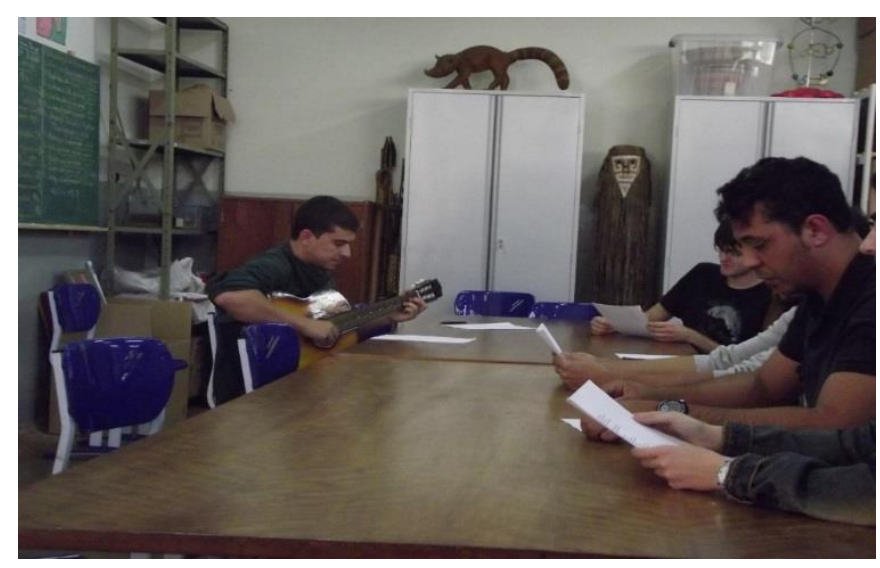

Fig. 2: Apresentação da música

Em seguida, com o intuito de dialogar com o tema transversal Meio Ambiente, descrito no PCN, o professor iniciou as discussões sobre a música. Segundo o PCNTemas transversais (1998), perceber-se integrante e agente transformador do ambiente, identificando seus elementos e as interações entre eles, contribui ativamente para a melhoria do meio ambiente. Nessa perspectiva, o aluno deve compreender as 
relações de exploração entre o homem e a natureza e os impactos ambientais e sociais que essa relação traz.

Tendo como base essas considerações, o professor iniciou a discussão, pedindo aos alunos que identificassem questões ambientais que estavam presentes na música. Foi destacado pelos alunos a construção de usinas hidrelétricas e a necessidade de produção de energia, ressaltando que, direta ou indiretamente, o ser humano é um agente transformador do ambiente. A partir disso, o professor fez uma ligação com os impactos ambientais e sociais causados por uma usina hidrelétrica. Dessa maneira, foram levantadas questões como a desapropriação de terras dos produtores rurais para a construção da usina e também os impactos causados às plantas da região da usina. De modo a aproximar o conteúdo dos alunos, o professor citou como exemplo uma usina que existe na região de Lavras - MG. Para isso, destacou algumas espécies de plantas da região que tem hoje em dia, alguns exemplares submersos devido ao represamento.

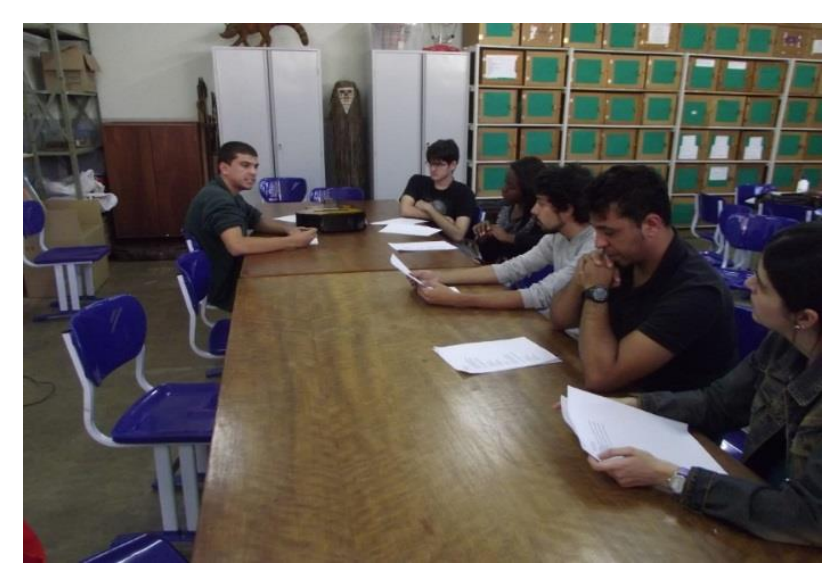

Fig. 3: Discussão sobre questões ambientais presentes na música.

Dando continuidade à aula, o professor pediu aos alunos que levantassem outros impactos ambientais que tem influência na vegetação regional. Foram levantados os impactos envolvidos na plantação de eucalipto, queimadas, mineração, depósito de lixo e a construção civil. Foi feita então uma discussão sobre essas questões, que serviria de subsídio para a próxima etapa da aula. 


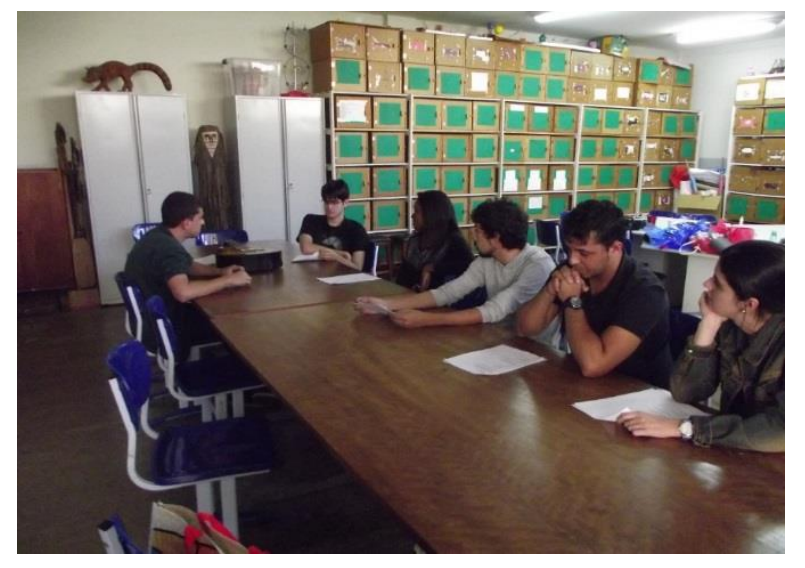

Fig. 4: discussão sobre outros impactos presentes na região.

Na última etapa da aula, o professor pediu aos alunos que se dividissem em dois grupos e fizessem uma paródia da música apresentada inicialmente, sobre alguns conceitos trabalhados durante a aula. Ao final, as duas paródias seriam unidas em uma única, juntamente com uma parte feita pelo professor e uma parte original da música. Na paródia construída, além da parte original da música que fala das barragens de usinas hidrelétricas e os impactos que elas causam, foram destacadas as questões envolvidas nas grandes plantações, nas queimadas e na necessidade de progresso da sociedade, que não tomam consciência dos problemas ambientais que podem ser causados. Foram destacadas ainda, algumas espécies de plantas que são afetadas pelos impactos ambientais da região.

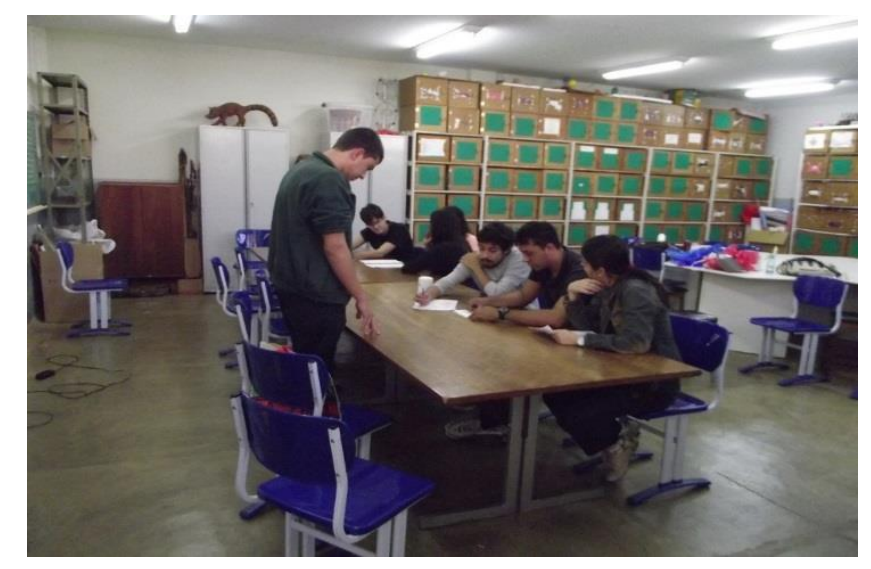

Fig. 5: construção da paródia. 


\section{Música final produzida pelos alunos}

O homem chega, já desfaz a natureza

Tira gente, põe represa, diz que tudo vai mudar

O São Francisco lá pra cima da Bahia

Diz que dia menos dia vai subir bem devagar

E passo a passo vai cumprindo a profecia do beato que dizia que o Sertão ia alagar

O sertão vai virar mar, dá no coração

O medo que algum dia o mar também vire sertão

O fogo chega e já destrói a natureza

Tira a vida e trás tristeza

pro homem poder plantar

E até mesmo a vegetação nativa

Que um dia foi bonita

Corre o risco de acabar

E passo a passo vai cumprindo a profecia

Que a queimada é destrutiva e com tudo vai acabar

A natureza vai mudar

Dá no coração

O medo que algum dia

Tudo vire plantação

O homem chega e diz barbaridades

Tira gente e põe madeira

Diz que tudo é pra plantar

É tudo clonagem, mas cadê a diversidade

Diz que dia menos dia o progresso ia chegar

E passo a passo vai mudando a natureza

Do beato que dizia que a plantação ia alastrar

Meu quintal vai acabar

Só tem plantação

Com receio de um dia

Só ter lenha na minha mão

Candeia, arueira, goiabeira e ipê

Tudo isso aí não vai ter

Samambaia, amoreira, Barba-de-bode e Imbuia, Pé de Cedro

Adeus, adeus

Dando continuidade, o professor voltou a reproduzir a música, cantando dessa vez a paródia construída. Para finalizar, o professor fez uma nova problematização, dessa vez sobre a paródia que foi produzida. Nessa parte, o professor buscou trabalhar 
novamente com o tema transversal Meio Ambiente em conjunto com o tema transversal Ética, ambos presentes no PCN. Para isso, levantou questões relacionadas aos impactos ambientais causados pelo ser humano ao ambiente em que vivem, ressaltando a maneira que o ser humano prejudica a si mesmo e aos outros seres vivos que também vivem nesse mesmo local.

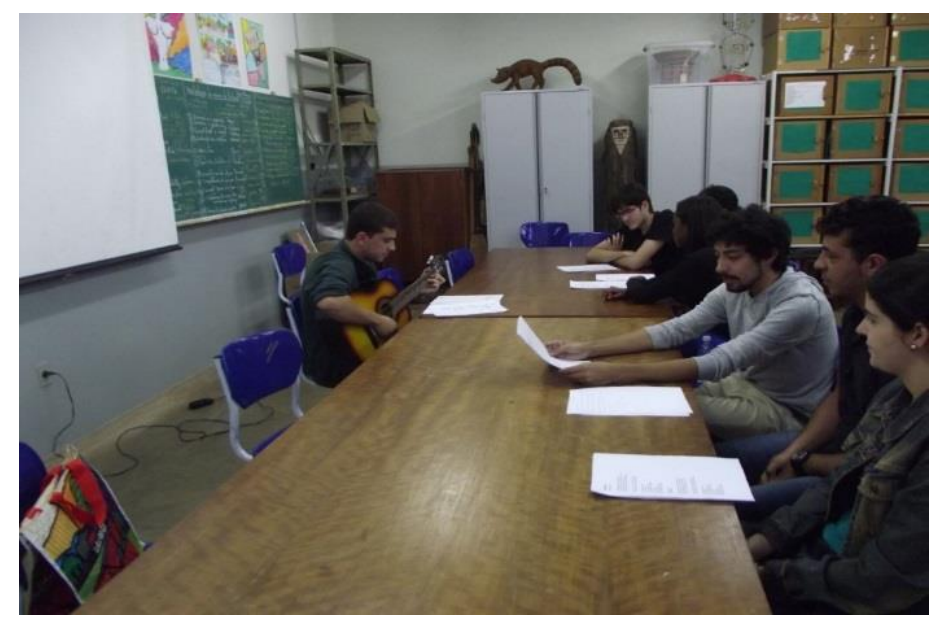

Fig.6: apresentação da paródia construída.

\section{Quarto momento: avaliação da aula}

Para finalizar, os alunos da disciplina que participaram da prática, avaliaram a aula e a estratégia pedagógica utilizada. Para manter sigilo, os alunos serão identificados pela letra A (aluno).

A1: "Primeiramente parabéns, gostei muito da sua aula. Deu um clima de descontração na aula, principalmente pelo fato de você saber cantar e tocar violão. Você trabalhou nessa questão ambiental, com uma coisa que eu gosto muito que é a construção de hidrelétricas. Muito bom, parabéns.".

A2: "Cara, sensacional. Gostei demais. Adoro essa parte da música. Gostei tanto da sua prática que fiquei pensando aqui e tô sem o que falar até agora. Não vi defeito nenhum. Tô pensando nessa sua aula, numa sala com 30 alunos em roda, acho 
que dá uma vibe fenomenal. Acho que você deveria também expandir pra outros ritmos. Mas cara, demais.".

A3: "Parabéns, ficou muito legal. Porque você foi conversando com a gente e sem a gente perceber você já tava dando sua aula, achei muito legal. Só queria levantar uma questão, que é que você deveria mostrar imagens das plantas que você citou na música, pra gente se familiarizar. Fora isso, gostei muito, parabéns.".

A4: "Achei sensacional a sua aula, porque você já chega dizendo que é uma aula diferente e depois já mostra o violão. Tenho a impressão que o aluno vai adorar. $\mathrm{E}$ depois você já entra com o debate, achei sensacional. Principalmente esse jeito que você deu sua aula. Não me senti numa aula, me senti numa conversa. Isso me deixou muito confortável, creio que vá dar certo com os alunos também.".

A5: "Parabéns. Eu acho que você conseguiu muito bem conciliar prática, teoria, tema transversal e música. Achei muito legal porque o que pudemos perceber na sua aula é que dá pra se ensinar sem utilizar a exposição, mas muito pelo contrário, apenas conversando, investigando e problematizando com os alunos. Muito bom.".

\section{DISCUSSÃO}

O método avaliativo utilizado nas avaliações é o discurso. Segundo Macedo et al. (2008), através do discurso o sujeito revela sua compreensão sobre determinado contexto, no qual buscam termos para a produção do próprio discurso. Nesse sentido, ao avaliar o discurso dos alunos que avaliaram a prática, foi possível ressaltar algumas questões.

A partir das avaliações, pôde-se perceber que, em todas as falas, foram levantadas questões sobre as qualidades de uma aula não expositiva e da utilização de estratégias pedagógicas diferenciadas. Essas considerações vão de encontro com a pedagogia progressista. Segundo Gonçalves et al. (2012), ao contrário da tecnicista, a nova pedagogia valoriza o pensamento crítico dos alunos e exige uma pluralidade de metodologias de ensino. Dessa maneira, torna-se necessário que o professor explore 
melhor as metodologias de ensino para que seja possível utilizar outras metodologias, fugindo do método expositivo. Ainda nessa perspectiva, Oliveira e Coutinho (2009), dizem que os professores devem buscar por recursos didáticos que sejam capazes de instigar o interesse dos alunos para a aprendizagem, tornando possível melhorar o processo de ensino. Foi possível perceber então que essa maneira diferenciada de ministrar uma aula, quando citada nas avaliações, se encaixa como uma estratégia que estimula $o$ aluno e instiga $o$ interesse dos mesmos para a prática.

Foi possível perceber ainda, segundo A3, A4 e A5, a importância de utilizar o método investigativo no ensino. Por meio do método, em uma conversa, foi possível utilizar o conhecimento prévio dos alunos para problematizar as questões ambientais envolvidas na música e que se relacionam diretamente com a região na qual a cidade está inserida. Essas falas estão de acordo com o trabalho de Bell et al. (1985), no qual dizem que é importante utilizar o conhecimento prévio do aluno, através do método investigativo, pois essa prática instiga o aluno a participar ativamente da aula.

Além disso, na avaliação A4, foi destacada a importância de motivar o aluno, permitindo que o mesmo se sinta à vontade para participar da aula. Nascimento Júnior (1996) apud Grunvald et al. (2002) destacam que no momento em que a ciência e a arte se misturam durante o processo educativo há a motivação do aluno, permitindo que o mesmo participe ativamente da prática. Nesse sentido, é possível perceber a importância de estratégias relacionadas à arte, como a música, na motivação do aluno e consequentemente, em sua participação na construção do conhecimento pretendido.

\section{CONCLUSÃO}

Tendo como base o relato dos alunos da disciplina foi possível perceber que a metodologia cumpriu seu papel ao trabalhar a influência dos impactos ambientais nas plantas, trabalhando também os temas transversais ética e meio ambiente. É possível inferir ainda, sobre a aula, que a utilização de práticas pedagógicas não expositivas como a música e o método investigativo tornam a aula mais proveitosa e instigam a participação do aluno na prática. Pôde-se notar ainda a importância da motivação do aluno durante a prática, permitindo-o participar ativamente da aula. Nesse sentido, 
pode-se concluir que a busca por práticas pedagógicas alternativas é necessária, uma vez que as mesmas tem capacidade de estimular a participação do aluno na aula, aproximando-o do conhecimento e contribuindo positivamente para o processo de ensino-aprendizagem.

\section{REFERÊNCIAS}

BELL, B., WATTS, M. \& WILSON, C. (1985). Children's learning: Interactions between teachers and researchers. School Science Review, 66, pp. 651-657

BRASIL. Ministério de Educação. Parâmetros Curriculares Nacionais: terceiro e quarto ciclos:

Temas Transversais. Secretaria de Ensino Fundamental. Brasília: MEC/SEF, 1998.

FERREIRA, M. Como usar a música na sala de aula. 7. ed. São Paulo: Contexto, 2008.

GONÇALVES, L. V.; CORTEZ, M. T. J; SANT'ANA, C. R. O; NASCIMENTO JUNIOR, A. F. Utilização do teatro de fantoches como prática de ensino: um relato de experiência do PIBID de biologia da universidade federal de Lavras, MG. Revista de Ensino de Biologia da Associação Brasileira de Ensino de Biologia (SBEnBio), v. 5, p. 1-10, 2012.

GRUNVALD, A. K.; VIVIAN, D. A.; SOUZA, S. C.; ANSOLIN, T. L.; LIMA, S.; TEIXEIRA, V. L.; NASCIMENTO JÚNIOR, A. F. Oficinas de papel maché, E.V.A ( evenil venílico acetilico) e bordado como subsídios ao ensino de biologia. Anais do I Encontro Nacional de Difusão Tecnológica. Medianeira: CEFER, 2002. p. 208-209.

MACEDO, L.C.; LAROCCA, L. M.; CHAVES, M. M. N.; MAZZA, V. A. ANÁLISE DE DISCURSO: uma reflexão para pesquisar em saúde. Interface. Comunicação, Saúde e Educação, v. 12, p. 649-657, 2008.

MINAS GERAIS. Secretaria do Estado de Educação. Conteúdo Básico Comum: CBC Biologia. Belo Horizonte: SEE, 2007.

MORIN, E. Saberes Globais e Saberes Locais - o olhar transdisciplinar. Rio de Janeiro: Garamond, 2000.

OLIVEIRA, N. M. F.; COUTINHO, F. A. A influência das cores na identificação e interpretação de imagens no ensino de ciências. Encontro nacional de pesquisa em educação em Ciências. Florianópolis, 2009.

PARIZE, M. Educação e música, um casamento que dá certo. IBEP, 2003. Disponível em $<$ http://www.eaprender.com.br/tiki_smartpages_View.php? pageld=942 > Acesso em: 01/09/2014 